\title{
Ocorrência de lesões em praticantes de musculação em academias de duas cidades brasileiras
}

\author{
Occurrence of injuries in bodybuilder in academies of two cities of Brazil \\ Ocurrencia de lesiones en culturistas en academias de dos ciudades de Brasil \\ Thais da Silva CHAGAS ${ }^{1}$ \\ Lívia DELLALLIBERA ${ }^{1}$ \\ Andressa Della TORRE ${ }^{1}$ \\ Andriele Carolina RAIMUNDO ${ }^{1}$ \\ Anderson MARTELLI ${ }^{2}$ \\ Taiguara Bertelli COSTA ${ }^{3}$ \\ Lucas DELBIM ${ }^{4}$
}

${ }^{I}$ Graduação em Educação Física Centro Universitário de Jaguariúna UNIFAJ, Município de Jaguariúna - SP, Brasil

${ }^{2}$ Mestre em Ciências Biomédicas Uniararas; Docente do Curso de Educação Física da Faculdade Mogiana do Estado de São Paulo - Município de Mogi Guaçu - SP

${ }^{3}$ Doutor em Gerontologia - FCM - UNICAMP. Coordenador e Docente do Curso de Educação Física da UNIFAJ, Município de Jaguariúna - SP, Brasil

${ }^{4}$ Mestre em Sustentabilidade e Qualidade de Vida-(UNIFAE). Docente do Curso de Educação Física da UNIFAJ, Município de Jaguariúna-SP, Brasil

\section{Resumo}

Objetivo: O presente estudo investigou 170 indivíduos de ambos os sexos em três academias do município de Mogi Guaçu/SP e uma de Mogi-Mirim/SP, verificando relato de ocorrência de lesões aos praticantes de musculação. Método: A coleta de dados ocorreu através de um questionário semiestruturado, onde determinou às práticas realizadas nas academias e o número de relatos de lesões nesses praticantes. Resultado: Os tipos de lesões mais frequentes entre o gênero masculino foi luxação e no feminino, distensão. Quanto ao local mais acometido foram ombro no gênero masculino e região lombar no feminino. Conclusão: Os resultados apontam que as lesões ocorridas nos praticantes de musculação se devem a prática de exercícios intensos realizados com cargas superiores ao que seu corpo está apto, gerando uma sobrecarga muito grande nas articulações ocasionando lesões que os impossibilitam de dar continuidade ao treinamento. As investigações foram exclusivamente por percepção individual, e a presente proposta não aspirou construir hipóteses sobre as ocorrências relatadas.

Descritores: Músculos; Ferimentos e Lesões; Academias de Ginástica.

\section{Abstract}

Objective: The present study investigated 170 individuals of both sexes in three academies in the city of Mogi Guaçu / SP and one in MogiMirim / SP, verifying reports of the occurrence of injuries to bodybuilders. Method: Data were collected through a semi structured questionnaire, which determined the practices performed in the academies and the number of reports of injuries in these practitioners. Result. The most frequent types of lesions among the male gender were dislocation and female distension. As to the most affected site was shoulder in the male gender and lumbar region in the female. Conclusion: The results indicate that the injuries occurring in bodybuilders are due to the practice of intense exercises performed with loads higher than their body is fit, generating a great overload in the joints causing injuries that make it impossible to continue the training. The investigations were exclusively by individual perception, and the present proposal did not aspire to construct hypotheses about the reported occurrences.

Descriptors: Muscles; Wounds and Injuries; Fitness Centers.

\section{Resumen}

Objetivo: El presente estudio investigó a 170 individuos de ambos sexos en tres academias del municipio de Mogi Guaçu / SP y una de Mogi-Mirim / SP, verificando relato de ocurrencia de lesiones a los practicantes de musculación. Método: La recolección de datos ocurrió a través de un cuestionario semiestructurado, donde determinó a las prácticas realizadas en los gimnasios y el número de relatos de lesiones en esos practicantes. Resultado: Los tipos de lesiones más frecuentes entre el género masculino fueron luxación y en el femenino distensión. En cuanto al lugar más acometido fueron hombro en el género masculino y región lumbar en el femenino. Conclusión: Los resultados apuntan que las lesiones ocurridas en los practicantes de musculación se deben a la práctica de ejercicios intensos realizados con cargas superiores a lo que su cuerpo está apto, generando una sobrecarga muy grande en las articulaciones ocasionando lesiones que los imposibilitan de dar continuidad al entrenamiento. Las investigaciones fueron exclusivamente por percepción individual, y la presente propuesta no aspiró a construir hipótesis sobre las ocurrencias relatadas.

Descriptores: Músculos; Heridas y Traumatismos; Centros de Acondicionamento.

\section{INTRODUÇÃO}

Atualmente a conscientização em assegurar melhor qualidade de vida e bem estar vem mudando de forma significativa o estilo de vida das pessoas, o qual tende a ser mais ativo, por meio da prática de atividades físicas ${ }^{1}$. Estudos retratam que a atividade física promove inúmeros benefícios imediatos como a regularização dos níveis de glicose sanguínea, perfil lipídico, quantidade e qualidade do sono e a longo prazo melhora do sistema cardiovascular, flexibilidade, resistência, potência e força muscular, equilíbrio, coordenação e velocidade de movimento ${ }^{2}$.

Alves et al. ${ }^{3}$ apontam que é cada vez mais evidente que a insatisfação corporal é uma realidade para ambos os sexos e que o enquadramento corporal nos padrões estéticos estabelecidos culturalmente tem levado os indivíduos à procura de recursos como a prática de exercícios físicos exagerados podendo estabelecer um quadro lesivo. Mueller e Maluf ${ }^{4} \mathrm{e}$ Faulkner ${ }^{5}$ definem lesão como qualquer alteração tecidual que resulte em dor ou desconforto acarretando perda de funcionalidade do músculo, levando a perda de desempenho na promoção de suas atividades. Rekola et al. ${ }^{6}$ descrevem que o sistema musculoesquelético é o mais acometido.

As lesões crônicas são determinadas por um início tardio dos sintomas, acarretando a diminuição da eficiência dos movimentos, entretanto, não incapacita totalmente o atleta. A persistência da realização das atividades que ocasiona a lesão e a falta de cuidados e reabilitação terá como consequência lesões graves, levando o atleta ou praticante a impossibilidade de realizar suas 
atividades no esporte e atividades do cotidiano ${ }^{7}$.

Wagner $^{8}$ descreve que a execução incorreta de exercícios e o uso de cargas elevadas que muitas vezes os próprios praticantes acabam não resistindo podem ser justificativas pelo aumento gradual de lesões musculares que vem acontecendo em academias com praticantes de musculação. Cada pessoa apresenta características individuais que levam o músculo resistir à determinadas cargas, fatores extrínsecos como os alimentos ingeridos, fadiga, condição emocional e psicológica, o ambiente frequentado e os aparelhos utilizados e principalmente os fatores intrínsecos como o sexo, a idade, situação física, condição fisiológica e muitos outros.

Segundo Reeves et al. ${ }^{9}$, observa-se que principalmente a execução incorreta, a falta de orientação e supervisão de profissionais capacitados, imaturidade esquelética, o uso decorrente de esteroides anabolizantes são condições que contribuem diretamente nas lesões, e isso pode transcorrer em consequência da ausência ou realização mínima de aquecimento antes de iniciar a prática da musculação, perda de estabilidade durante a execução de determinados exercícios culminando na realização de movimentos errôneos, contrações excessivas e aceleradas resultando em lesões musculares.

Exercícios intensos ou demasiadamente repetitivos combinados a uma má orientação podem levar a lesões musculares nas academias. A falta de conhecimento do professor sobre seu aluno, seu histórico de lesões ou até mesmo uma lesão não tratada pode ocorrer um agravamento. Assim, o objetivo do presente estudo foi avaliar a ocorrência de lesões em praticantes de exercícios resistidos (ER) com faixa etária entre 18 e 40 anos em três academias do município de Mogi Guaçu/SP e uma de MogiMirim/SP. Através dos dados obtidos na pesquisa será possível a construção de um panorama, mesmo que parcial localizado em uma microrregião.

\section{MATERIAL E MÉTODO}

Foram submetidos à avaliação 170 alunos de três academias da cidade de Mogi Guaçu/SP e uma academia da cidade de Mogi Mirim/SP, com faixa etária de 18 a 40 anos, que após os esclarecimentos sobre os objetivos e a metodologia da pesquisa, comprovaram seu aceite em participar da presente proposta mediante assinatura do Termo de Consentimento Livre e Esclarecido (TCLE), projeto aprovado pelo Comitê de Ética em Pesquisa do Centro Universitário de Jaguariúna, CAAE: 69257517.7.0000.5409, sendo observados todos os parâmetros relacionados à ética em pesquisa com seres humanos que constam na Resolução 466 do CONEP de 2012.

O formato de avaliação foi por meio de questionário semiestruturado, onde determinou o número de relatos de lesões nesses praticantes e as possíveis causas. Os respondentes preencheram o questionário de forma autônoma e anônima, sem ajuda ou supervisão de qualquer indivíduo.

Como critérios de inclusão da amostra na pesquisa, foram analisadas informações comprobatórias sobre a situação do aluno na academia, idade acima de 18 anos e o aceite formal em participar da pesquisa com a assinatura do TCLE. Como critério de exclusão, não estar frequentando regularmente uma academia, idade inferior a 18 anos e pelo não consentimento em participar da pesquisa.

Após a coleta de dados, as informações foram digitadas e tabuladas em banco de dados do programa Microsoft Excel - 2010 para as análises estatísticas de frequência, média e desvio padrão. Posteriormente foi realizada uma comparação dos resultados observados com os descritos na literatura.

\section{RESULTADOS E DISCUSSÃO}

De acordo com os resultados obtidos, 45 participantes, isto é, $23 \%$ da amostra total já sofreu algum tipo de lesão na academia e a maior ocorrência foi observada no gênero masculino $(n=28-62 \%)$, Figura 1. Este fator pode ser explicado por alguns fatores, porém, nenhum deles foi medido ou avaliado pela presente proposta. Todavia, estudos semelhantes apontam que indivíduos do sexo masculino tendem a utilizar sobrecarga de forma constante em relação as mulheres. Soma-se a este excesso de carga, a necessidade mecânica de se desconstruir o movimento original para geral vantagem mecânica extra e, às vezes, amplitudes excessivas, maior índice de lesões musculares e ligamentares poderão ser observados.

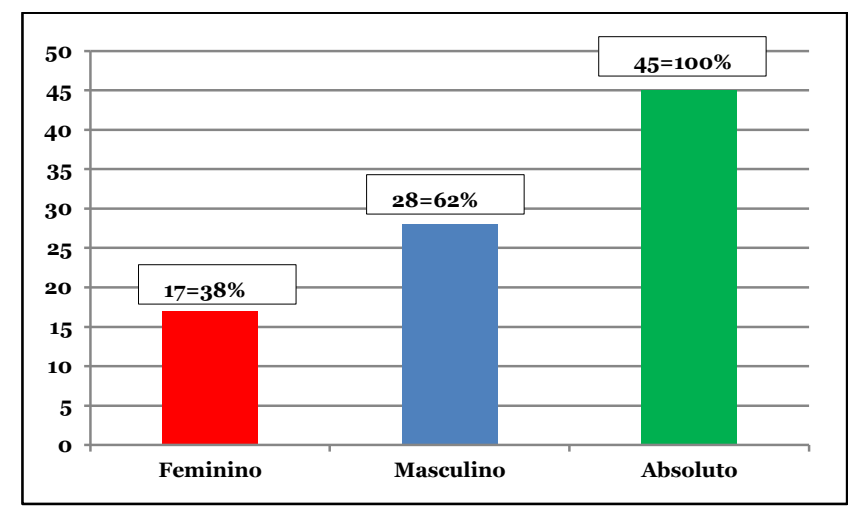

Figura 1: Ocorrência de lesões por gênero (Fonte: dados da pesquisa).

Um estudo sobre a percepção de lesões em adultos praticantes de musculação realizado por Souza et al. ${ }^{10}$, com uma amostra constituída por 45 indivíduos (37,49 $\pm 11,51$ anos) de ambos os gêneros, foi observado que quase metade da amostra $(44,4 \%)$ apresentou alguma lesão num período retroagido de oito meses e os resultados deste estudo indicaram que essas lesões estão relacionadas a exercícios realizados incorretamente, juntamente com métodos 
de treinamento inadequados, utilização de cargas elevadas e ausência do acompanhamento de um profissional durante a prática de musculação. Desta maneira faz-se necessário conscientizar os praticantes sobre a importância do acompanhamento por um profissional qualificado da área de Educação Física.

Martins et al. ${ }^{11}$, em estudo objetivando identificar a incidência de lesões musculoesqueléticas em praticantes de musculação nas academias de ginástica de Guanambi-BA, cuja amostra era formada por 400 indivíduos, mais da metade dos indivíduos analisados (64\%) relataram ter sofrido alguma lesão, sendo que $59 \%$ destes, acreditavam que a lesão estava relacionada às atividades realizadas na academia. No estudo de Silva ${ }^{7}$, que analisou a frequência de lesões em praticantes de musculação em ambiente de academia, e na relação de incidência dessas variáveis, os resultados apontam que $70 \%$ da amostra apresentou algum tipo de lesão, sendo que, 25 das mulheres que foram entrevistadas $40 \%$ delas apresentaram lesão, devido exercícios mal executados, e 25 dos homens entrevistados, $80 \%$ apresentaram algum tipo de lesão, sendo a principal causa o excesso de carga seguido por treinamento excessivo.

Em referencia a tipificação das lesões, a Figura 2 apresenta as ocorrências dessas lesões apresentando um panorama corporal de maior ou menor incidência, sendo a luxação, a lesão de maior ocorrência, seguido de caibra e lesão de ligamento respectivamente na avaliação geral. Quando avaliada por gênero, a luxação apresentou maior ocorrência nos homens, seguido de caibras e lesões de ligamento e nas mulheres, distensões musculares, seguido de luxação e lombalgia.

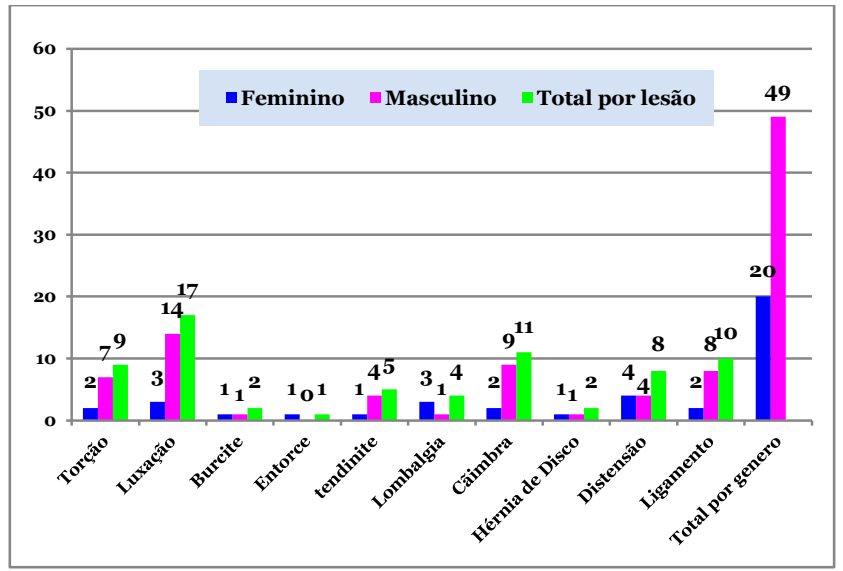

Figura 2: Tipificação de lesão (Fonte: dados da pesquisa).

Em relação à localização corporal das lesões, observou-se maior ocorrência para a região de lombar, seguida do ombro e joelho. No comparativo por gênero, os resultados obtidos destacam que o maior índice de lesões no gênero masculino foi no ombro seguido de lesões no joelho e quadríceps; no gênero feminino as lesões foram maiores na região lombar, seguido do joelho e ombro (Figura 3 ).

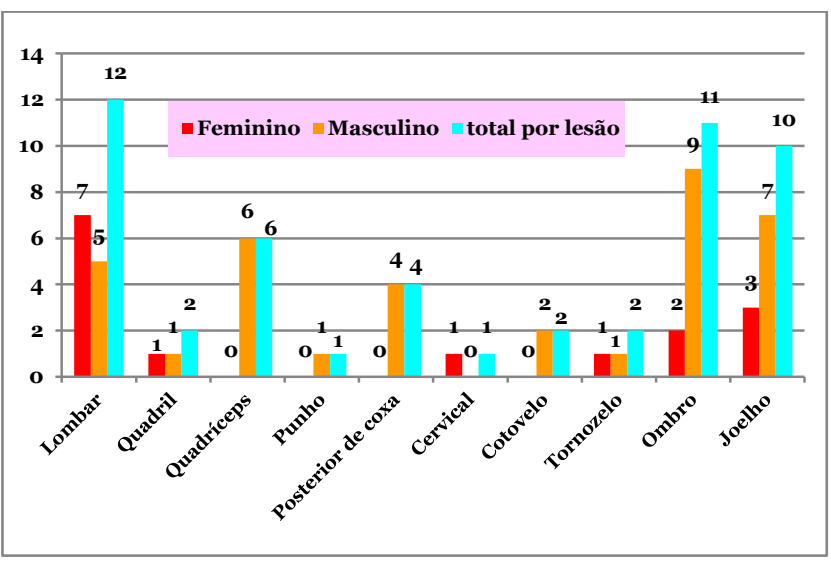

Figura 3: Localização das lesões (Fonte: dados da pesquisa).

Os dados corroboram com aqueles obtidos em estudo realizado por Moreira et al. ${ }^{12}$, que analisou lesões corporais mais frequentes em alunos da academia de ginástica e musculação de Ituaçu - BA, onde foram encontradas lesões em articulações, sendo as mais comuns nos joelhos, por ser composto por uma estrutura complexa envolvendo ligamentos, meniscos e tendões, ocasionando lesões devido ao excesso de peso e ao impacto. Foi observado também lesões na coluna, seguida pelo ombro, quadril, cotovelo, tórax e panturrilha na realização de exercício com postura inadequada e sobrecarga nestas regiões.

Souza et al. ${ }^{10}$ em pesquisa com 45 indivíduos observaram que a distensão muscular foi o tipo de lesão mais relatado em sua amostra, respondendo $35 \%$, e ombro e joelho foram os locais anatômicos com maior ocorrência de lesão corroborando com os dados observados neste estudo. Martins et al. ${ }^{11}$ analisando frequentadores de academia, verificaram que $\mathrm{o}$ joelho foi $\mathrm{o}$ segmento corporal mais frequentemente lesionado (31\%), seguido por ombro (19\%), punho (19\%) e coluna (17\%).

Em relação à temporalidade das lesões, ficou evidente que a maioria dos informantes atribui a ocorrência há mais de seis meses e do total de indivíduos lesionados, $60 \%$ deles associaram a lesão a pratica de exercícios resistidos. Segundo constatações, as razões para as lesões mais ocorridas em ambos os gêneros foram: carga excessiva, desvio postural e falta de fortalecimento. Nas mulheres, $17 \%$ retrataram que a carga excessiva foi um fator de gênese lesiva, desvio postural $6 \%$ e a falta de fortalecimento $4 \%$. Entre os homens, $20 \%$ apontam carga excessiva, desvio postural $15 \%$ e falta de fortalecimento $15 \%$.

Entre as atitudes tomadas após as lesões destacam-se que $8 \%$ das mulheres continuaram as atividades normalmente, $17 \%$ deixaram de fazer algumas atividades e $6 \%$ deixaram de realizar todas as atividades. Entre os homens, $17 \%$ continuaram as atividades, $35 \%$ abandonaram algumas atividades e $6 \%$ deixaram de realizar todas as atividades. Liz e Andrade $^{13}$ avaliaram praticantes de musculação e 
verificaram que a desistência por motivo de lesão ficou em segundo lugar, atrás apenas da falta de tempo para execução dessa atividade.

\section{CONCLUSÃO}

O presente estudo foi realizado com o intuito verificar as possíveis lesões musculares e de estruturas correlatas ao sistema muscular esquelético em praticantes de exercícios resistidos e analisar prováveis causas que levaram a este fenômeno, tipos de lesões frequentes e os locais que mais sofreram com essas lesões. Foi verificado que grande parte dos praticantes de exercícios em academia não apresentou nenhum tipo de lesão decorrente da prática de musculação.

Contudo, os resultados apontam que as lesões ocorridas nos praticantes de musculação devem-se à pratica de exercícios intensos realizados com cargas superiores ao que seu corpo está apto, gerando uma sobrecarga intensa nas articulações. Foi possível verificar há falta de acompanhamento por parte dos professores com seus alunos, levando os mesmos a executarem movimentos de maneira incorreta, conciliando a má postura na realização de exercícios.

Ressaltamos a falta de fortalecimento muscular, e a realização de treinamentos volumosos e/ou intensos poderá favorecer a ocorrências de lesões constatando-se a necessidades das academias e professores apresentarem como diferencial a formação pessoal e qualidade nos atendimentos.

\section{REFERÊNCIAS}

1. Marinho A, Guglielmo LGA. Atividade Física na Academia: Objetivos dos Alunos e suas Implicações. In: Congresso Brasileiro de Ciências do Esporte, 2, 1997. Anais, 1997: 1214.

2. Rolla AFL, Zibaoui N, Sampaio RF, Viana SO. Análise da percepção de lesões em academias de ginástica de Belo Horizonte: um estudo exploratório $\mathrm{R}$ Bras $\mathrm{Ci}$ e Mov. Brasília. 2004;12(2):7-12.

3. Alves D, Pinto M, Alves S, Mota A, Leirós V. Cultura e imagem corporal. Motricidade. 2009; 5:1-20.

4. Mueller MJE, Maluf KS. Tissue Adaptation to Physical stress: a proposed "physical stress theory" to guide physical therapist practice, education, and research. Phys Ther. 2002;82(4):383-403.

5. Faulkner JA, Brooks SV, Opiteck JA. Injury to skeletal muscle fibers during contractions: conditions of occurrence and prevention. Phys Ther. 1993;73(12):911-21.

6. Rekola KE, Keinänen-Kiukaanniemi SE, Takala J. Use of primary health services in sparsely populated country districts by patients with musculoskeletal symptoms: consultations with a
Physician. J Epidemiol Community Health. 1993;47(2):153-57.

7. Silva AVA. Incidência de lesões em praticantes de musculação em ambiente de academia [monografia]. Campina Grande: Universidade Estadual da Paraíba - UEPB; 2010.

8. Wagner E. Estudo de lesões musculares e articulares em praticantes de musculação de uma academia do município de Florianópolis-SC [monografia]. Florianópolis: Universidade Federal de Santa Catarina - UFSC; 2013.

9. Reeves ND, Maganaris CN, Narici MV. Effect of strength training on human patella tendon mechanical properties of older individuals. J Physiol. 2003; 548(Pt 3): 971-81.

10. Souza GL, Moreira NB, Campos W. Ocorrência e características de lesões entre praticantes de musculação. Saúde e Pesquisa. 2015;8(3):469-77.

11.Martins APC, Gomes AGS, Pereira GS, Fernandes LS, Badaró RR, Alves TCF. Incidência de lesões em praticantes de musculação nas academias de ginástica da cidade de Guanambi BA. Disponível em: http://docplayer.com.br/68068144-Palavras-chave -atividade-fisica-lesoes-musculoesqueleticasmusculacao.html.

12.Moreira RM, Boery EM, Boery RN. Lesões corporais mais frequentes em alunos da academia de ginástica e musculação de Ituaçu, Bahia. EFDesportes. 2010;15(151): http://www.efdeportes.com/

13.Liz CM, Andrade A. Análise qualitativa dos motivos de adesão e desistência da musculacão em academias Rev Bras Ciênc Esporte. 2016;38(3):267-74.

\section{CONFLITO DE INTERESSES}

Os autores declaram não haver conflitos de interesse.

\section{AUTOR PARA CORRESPONDENCIA}

\section{Anderson Martelli}

martellibio@hotmail.com

Submetido em 26/12/2018

Aceito em 12/03/2019 